\title{
Organic Atmospheric Particulate Material
}

\author{
John H. Seinfeld ${ }^{1 *}$ and James F. Pankow ${ }^{2}$ \\ ${ }^{I}$ Divisions of Chemistry and Chemical Engineering, and Engineering and Applied \\ Science, California Institute of Technology, Pasadena, California 91125; \\ email: seinfeld@caltech.edu \\ ${ }^{2}$ Department of Environmental Science and Engineering, OGI School of Science \\ \& Engineering, Oregon Health \& Science University, Portland, Oregon 97291-1000; \\ email: pankow@ese.ogi.edu
}

Key Words atmospheric chemistry, aerosols, gas-particle partitioning, secondary organic aerosols, biogenic hydrocarbons

- Abstract Carbonaceous compounds comprise a substantial fraction of atmospheric particulate matter (PM). Particulate organic material can be emitted directly into the atmosphere or formed in the atmosphere when the oxidation products of certain volatile organic compounds condense. Such products have lower volatilities than their parent molecules as a result of the fact that adding oxygen and/or nitrogen to organic molecules reduces volatility. Formation of secondary organic PM is often described in terms of a fractional mass yield, which relates how much PM is produced when a certain amount of a parent gaseous organic is oxidized. The theory of secondary organic PM formation is outlined, including the role of water, which is ubiquitous in the atmosphere. Available experimental studies on secondary organic PM formation and molecular products are summarized.

\section{INTRODUCTION}

Aerosol particulate material (PM) in the atmosphere affects the climate by absorbing and scattering solar radiation, and by altering the properties and lifetimes of clouds (1). It has also been implicated in human disease and mortality (2). Atmospheric particles range in diameter from a few nanometers to tens of micrometers, and contain a myriad of chemical species. The major categories of atmospheric PM are inorganic salts, siliceous crustal minerals, carbonaceous materials, and water. Whereas the inorganic salt and mineral fractions are generally amenable to good chemical characterization, and reliable techniques certainly exist to measure particulate-phase water, the great complexity of the carbonaceous fraction poses analytical problems that currently prevent the compositional determinations needed by those interested in predicting/modeling the chemical, physical, and concentration aspects of atmospheric PM. This is problematic because $(a)$ the

${ }^{*}$ Corresponding author. 
mass fraction of carbonaceous material in "fine particles" (diameters $\leq 2.0 \mu \mathrm{m}$ ) is frequently second only to that of sulfate; and (b) particles in this size range are responsible for virtually all of the important climatic, visibility, and human health effects associated with atmospheric aerosols.

PM carbon has traditionally been divided into three fractions: organic carbon (OC), elemental carbon (EC), and carbonate carbon. The latter derives almost exclusively from soil dust. EC is a strong absorber of visible and near-IR light, and so has also been referred to as "black carbon." Viewed as a wholly nonvolatile material, EC is taken to exist only in the particle phase. The compounds making up OC, on the other hand, vary in volatility and can exchange with the gas phase in a manner that depends on that compound-dependent volatility (see below). The fact that particulate OC is always an aggregate mix of countless individual compounds that possess a wide range of chemical and thermodynamic properties makes measurements of particulate OC concentration difficult using any single direct analytical technique. Moreover, the analytical distinction between the OC and $\mathrm{EC}$ fractions is currently not well defined. This is because the very low volatilities and solubilities of the high molecular weight organic constituents of PM OC make such compounds behave increasingly like EC in analytical procedures. For example, within the polycyclic aromatic hydrocarbon (PAH) compound class, a simple structural extrapolation to very high molecular weight leads directly to EC. Current analytical methodologies are therefore forced to make operational distinctions between $\mathrm{OC}$ and $\mathrm{EC}$, with the cut then depending on the particular method used to perform the measurement $(3,4)$. In most methods, EC is operationally defined as that portion of the aerosol carbon that is resistant to decomposition under inertgas, high-temperature conditions. In practice, the current determination of aerosol $\mathrm{EC}$ and $\mathrm{OC}$ is further complicated by a variety of sampling and analysis artifacts, useful discussions of which are provided by Jacobson et al. (3) and Turpin et al. (4).

PM may be either directly emitted into the atmosphere (primary PM), or formed in situ (secondary PM). Secondary PM may result from the homogeneous nucleation of gaseous species, or from the condensation of gaseous species on existing particles. Both primary and secondary PM can be of either natural or anthropogenic origin. The relative contributions of primary and secondary sources to ambient PM depend on the nature and strengths of the local emissions, and on meteorological and chemical conditions in the atmosphere. EC is generally viewed as only coming from primary emissions, a property that has made EC a very useful tracer for the primary component of atmospheric PM.

Particulate organic PM emitted directly into the atmosphere, for example as products of fossil fuel combustion or biomass burning, is frequently referred to as primary organic aerosol (POA). By contrast, particulate organic PM that is formed in the atmosphere when the oxidation products of certain volatile organic compounds (VOCs) condense on pre-existing aerosols is frequently referred to as secondary organic aerosol (SOA). However, at any given time, there is only one aerosol present, and both secondary and primary particles may simultaneously contribute to the ensemble of particles making up that aerosol. Moreover, some 
individual particles may well be mixtures of both primary and secondary OC materials. Suitable representations of these two quantities are then $\mathrm{PM}_{\mathrm{OC}, \mathrm{p}}$ and $\mathrm{PM}_{\mathrm{OC}, \mathrm{s}}$, with units of $\mu \mathrm{g} \mathrm{m}^{-3}$. The EC component is then $\mathrm{PM}_{\mathrm{EC}}\left(\mu \mathrm{g} \mathrm{m}^{-3}\right)$.

\section{PRIMARY CARBONACEOUSPM}

Primary carbonaceous PM can enter the atmosphere in many ways, including as particles from fossil fuel combustion; open biomass burning and residential wood combustion; disposal activities involving incineration; meat cooking; road, tire, and brake abrasion; plant debris suspension; bacteria, virus, and spore suspension; wave and bubble breaking in water bodies; and the suspension of soil particles. Indeed, virtually any process that leads to particles being emitted into the atmosphere represents a potential source of atmospheric carbonaceous material. A limited review of these types of sources has been provided by Jacobson et al. (3). We also direct the reader to the work of M. O. Andreae on emissions from biomass burning, and to that of G. R. Cass and coworkers on anthropogenic combustion sources.

Globally, $45 \%$ of all EC emitted and 55\% of all primary OC emitted are estimated to originate from fossil fuel burning (Table 1). The anthropogenic portion

TABLE 1 Estimated global annual emissions of primary organic PM, elemental carbon (EC), and gaseous precursors to secondary organic PM

\begin{tabular}{|c|c|c|}
\hline Tracer & Compound & Emission $\left({\left.\operatorname{Tg~} y r^{-1}\right)}^{-1}\right.$ \\
\hline Primary organic $\mathrm{PM}^{\mathrm{a}}$ & & 81 \\
\hline $\mathrm{EC}^{\mathrm{a}, \mathrm{b}}$ & & 12 \\
\hline $\mathrm{I}^{\mathrm{c}}$ & $\begin{array}{l}\alpha \text {-pinene } \\
\beta \text {-pinene } \\
\text { Sabinene and terpenoid ketones } \\
\Delta^{3} \text {-carene }\end{array}$ & $\begin{array}{r}50 \\
33 \\
20 \\
6\end{array}$ \\
\hline $\mathrm{II}^{\mathrm{c}}$ & Limonene & 33 \\
\hline III $^{\mathrm{c}}$ & $\begin{array}{l}\alpha \text { and } \gamma \text {-terpinene } \\
\text { Terpinolene }\end{array}$ & $\begin{array}{l}1.4 \\
2.9\end{array}$ \\
\hline $\mathrm{IV}^{\mathrm{c}}$ & $\begin{array}{l}\text { Myrcene } \\
\text { Terpenoid alcohols } \\
\text { Ocimene }\end{array}$ & $\begin{array}{r}7 \\
30 \\
3\end{array}$ \\
\hline $\mathrm{V}^{\mathrm{c}}$ & Sesquiterpenes & 15 \\
\hline
\end{tabular}

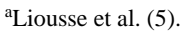

${ }^{\mathrm{b}}$ Penner et al. (9).

${ }^{\mathrm{c}}$ Guenther et al. (41); Griffin et al. (42). 
of all primary carbonaceous PM (OC + EC) is mainly from fossil fuel and intentional biomass burning. Whereas Liousse et al. (5) provide the only global inventory of carbonaceous PM from biomass burning, multiple emission inventories of carbonaceous PM from fossil fuel burning are available, including those of Cooke \& Wilson (6) for EC, Cooke et al. (7) for EC and primary OC, and Bond (8) for EC. The emission factors that relate the mass of EC (or primary OC) emitted to the mass of fuel burned have been found to vary by several orders of magnitude for different fuel types and burning efficiencies, and so are highly uncertain. This uncertainty is partly the cause of the 4:2:1 ratio among the North American EC emission estimates for fossil fuel burning of $(a)$ Cooke \& Wilson (6), (b) Cooke et al. and Bond (7, 8), and (c) Penner et al. (9), respectively. Given that primary OC inventories are generally inferred from corresponding EC inventories, primary $\mathrm{OC}$ emission inventories for fossil fuel burning are even more uncertain.

\section{SECONDARY CARBONACEOUS PM}

Secondary organic PM is formed when VOCs are oxidized in the atmosphere to form higher polarity and therefore lower volatility reaction products that then condense and thereby increase the mass concentration of PM [e.g., see Schuetzle $\&$ Rasmussen (10); Pankow (11, 12); Odum et al. (13); Seinfeld \& Pandis (14); and Figure 1]. The reduction in volatility that accompanies the conversion of a "parent" VOC to an oxidized product is a result of the fact that adding oxygen and/or nitrogen to organic molecules reduces volatility. This is true regardless of whether the addition places alcohol, aldehyde, ketone, alkyl nitrate, nitro, and/or carboxylic acid groups on the parent compound. Because significant secondary organic PM will not condense unless low-vapor pressure products are formed, in general only those parent organic molecules with six or more carbon atoms are capable of producing oxidized products that are important in the formation of secondary organic PM. Both anthropogenic and biogenic VOCs can lead to secondary organic PM; on a global scale, biogenic VOCs are estimated to be the predominant cause of such PM, whereas in urban areas anthropogenic VOCs can be the dominant source.

The formation of secondary organic PM from a particular VOC is often described in terms of the fractional mass yield, $Y$, which relates how much PM is produced when a certain amount of a parent gaseous VOC is oxidized. The fractional mass yield $(Y)$ of PM produced from the oxidation of a parent gaseous hydrocarbon (HC) is defined as

$$
Y=\frac{M_{\mathrm{o}}}{\Delta \mathrm{HC}},
$$

where $M_{\mathrm{o}}\left(\mu \mathrm{g} \mathrm{m}^{-3}\right)$ is the mass concentration of secondary organic PM produced from the reaction of $\Delta \mathrm{HC}\left(\mu \mathrm{g} \mathrm{m}^{-3}\right)$ worth of gaseous $\mathrm{HC}$ (not including any condensed water therein). Although many laboratory studies (see later) have measured 


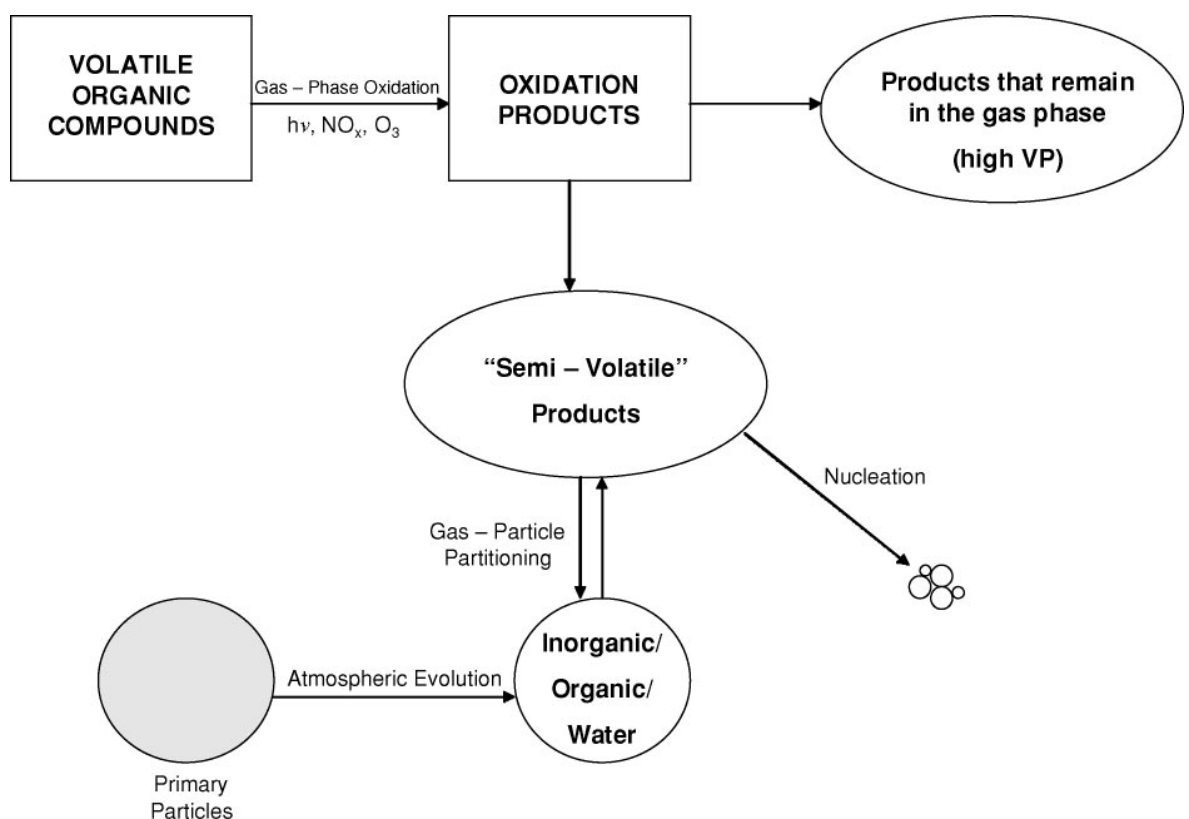

Figure 1 Route of formation of secondary organic particulate matter. Products of sufficiently low volatility, so-called "semi-volatile," may condense on pre-existing particles, which generally consist of inorganics, organics, and water, or nucleate homogeneously to form new particles.

yields from various specific parent HCs (e.g., cyclohexene and xylenes, as well as monoterpenes such as $\alpha$ - and $\beta$-pinene), it has proven difficult to obtain relatively complete molecular identifications and quantifications of the products making up those yields: The oxidation pathways are very complex and lead to multiple products, and the products are highly polar, difficult to identify, and may furthermore be quite reactive.

As discussed by Pankow et al. (15), laboratory yield data indicate that ( $a$ ) when only a very small amount of parent $\mathrm{HC}$ has reacted, $Y$ can be zero; $(b)$ as more product material accumulates, $Y$ values can become greater than zero; and $(c)$ further increases in products lead to further increases in $Y$ (see Table 1). Pankow et al. (15) further point out that although the formation of secondary organic PM from the simultaneous condensation of multiple products is more complex than the condensation behavior of a single component, a single-component system is analogous insofar as (a) no condensation will occur so long as the gas-phase pressure of the component remains below the saturation vapor pressure; $(b)$ the condensation yield will rise above zero once the amount of the compound per unit volume of air exceeds the saturation concentration; and $(c)$ the condensation yield will then continue to increase as more of the compound is added. 


\section{Theory of Secondary Organic PM Formation}

As discussed in detail by Pankow (11), once a multicomponent system contains enough condensable material to form aerosol, equilibrium gas/particle (G/P) partitioning is governed by the equation for absorptive gas/liquid partitioning in a potentially nonideal system, namely

$$
p_{i}=X_{i} \zeta_{i} p_{\mathrm{L}, i}^{o}
$$

where $p_{i}$ is the gas-phase partial pressure of species $i, X_{i}$ is the mole fraction of $i$ in the particle phase, $\zeta_{i}$ is the activity coefficient of species $i$ in the particle phase, and $p_{\mathrm{L}, i}^{\mathrm{o}}$ is the compound's vapor pressure as a pure liquid (subcooled if necessary) at the temperature of interest. As noted by Pankow et al. (15), rearrangement of Equation 1 yields a simple expression for $X_{i} / p_{i}$, which can be viewed as a form of $\mathrm{G} / \mathrm{P}$ partition coefficient in a multicomponent system:

$$
\frac{X_{i}}{p_{i}}=\frac{1}{\zeta_{i} p_{\mathrm{L}, i}^{\mathrm{o}}} .
$$

Equation 2 emphasizes the importance of $p_{\mathrm{L}, i}^{\mathrm{o}}$ and $\zeta_{i}$ in controlling G/P partitioning in SOA systems. Pankow et al. (15) discuss the facts that $(a)$ a low value of $p_{\mathrm{L}, i}^{\mathrm{o}}$ translates into a large value of the partition coefficient $X_{i} / p_{i}$ and therefore a high tendency for compound $i$ to be found in the particle phase; $(b)$ the $p_{\mathrm{L}}^{\mathrm{o}}$ values for atmospheric photooxidation products of interest span many orders of magnitude and extend down to very low values (e.g., $10^{-7}$ Torr); $(c)$ it is the low vapor pressure products that condense most readily to form secondary organic PM; $(d) \zeta_{i} \leq 1$ (compound $i$ is "comfortable" in the particle phase) favors condensation; and (e) for SOA cases of interest, $\zeta_{i}$ values typically lie in the range $0.3<\zeta_{i}<3$.

Low vapor pressures values are exceedingly difficult to measure by experimental laboratory techniques. Moreover, many such compounds are solids as pure compounds at ambient temperatures. As a result, difficult-to-measure $p_{\mathrm{S}}^{\mathrm{o}}$ values still need to be adjusted to obtain the needed subcooled $p_{\mathrm{L}}^{\mathrm{o}}$ values. The overall result is that the $p_{\mathrm{L}}^{\mathrm{o}}$ values of most SOA-relevant compounds are not known. As an alternative to experimental measurement, interest is gaining rapidly in computational methods that seek to predict $p_{\mathrm{L}}^{\mathrm{o}}$ values based on multiparameter correlations between structure and $p_{\mathrm{L}}^{\mathrm{o}}$. These include the SPARC method (16), the method of Makar (17), and UNIFAC-based approaches, including that of Asher et al. (18).

The common form of the gas/particle partitioning constant $K_{\mathrm{p}}$ for absorptive uptake into the particle phase was developed by Pankow (11) from Equation 2, namely:

$$
K_{\mathrm{p}, i}=\frac{(\mathrm{ng} / \mu \mathrm{g})_{\text {particle phase }}}{\left(\mathrm{ng} / \mathrm{m}^{3}\right)_{\text {gas phase }}}=\frac{F_{i} / \mathrm{TSP}}{A_{i}}=\frac{760 R T f_{\mathrm{om}}}{10^{6} \mathrm{MW}_{\mathrm{om}} \zeta_{i} p_{\mathrm{L}, i}^{\mathrm{o}}},
$$

where $p_{\mathrm{L}, i}^{\mathrm{o}}$ has units of Torr; $A_{i}\left(\mathrm{ng} \mathrm{m}^{-3}\right)$ is the concentration in the gas phase; $F_{i}$ $\left(\mathrm{ng} \mathrm{m}^{-3}\right)$ is the concentration in the largely organic material (OM) aerosol phase; 
$\operatorname{TSP}\left(\mu \mathrm{g} \mathrm{m}^{-3}\right)$ is the total suspended PM concentration; $R$ is the ideal gas constant $\left(8.2 \times 10^{-5} \mathrm{~m}^{3}\right.$-atm mol$\left.{ }^{-1} \mathrm{~K}^{-1}\right) ; T(\mathrm{~K})$ is temperature; $f_{\mathrm{om}}$ is the weight fraction of the TSP that comprises the absorbing OM phase; and $\mathrm{MW}_{\mathrm{om}}\left(\mathrm{g} \mathrm{mol}^{-1}\right)$ is the number-average molecular weight of the absorbing OM phase. We emphasize that the calculations of both $f_{\text {om }}$ and $\mathrm{MW}_{\mathrm{om}}$ include any water in the OM phase. The total mass/volume concentration $\left(\mu \mathrm{g} \mathrm{m}^{-3}\right)$ of the absorbing phase is (19)

$$
M_{\mathrm{t}}=M_{\mathrm{o}}+M_{\mathrm{w}}=f_{\mathrm{om}} \times \mathrm{TSP},
$$

where $M_{\mathrm{w}}\left(\mu \mathrm{g} \mathrm{m}^{-3}\right)$ is the mass concentration of water in the PM. (In cases wherein inorganic species besides water are also present in the absorbing PM phase, then $M_{\mathrm{t}}$ will be comprised of additional terms besides just $M_{\mathrm{o}}$ and $M_{\mathrm{w}}$.) Each $\zeta_{i}$ is a function of the aerosol composition, and each $p_{\mathrm{L}, i}^{\mathrm{o}}$ is a strong function of $T$. The pressure conversion factor 760 Torr/atm can, of course, be removed from the equation simply by selecting the same pressure units for $p_{\mathrm{L}, i}^{\mathrm{o}}$ and $R$.

Dividing both sides of Equation 3 by $f_{\text {om }}$ gives (13)

$$
K_{\mathrm{p}, \mathrm{om}, i}=\frac{(\mathrm{ng} / \mu \mathrm{g})_{\mathrm{om} \text { phase }}}{\left(\mathrm{ng} / \mathrm{m}^{3}\right)_{\text {gas phase }}}=\frac{F_{i} / M_{t}}{A_{i}}=\frac{760 R T}{10^{6} \mathrm{MW}_{\mathrm{om}} \zeta_{i} p_{\mathrm{L}, i}^{\mathrm{o}}},
$$

so that

$$
\frac{F_{i}}{A_{i}}=M_{\mathrm{t}} K_{\mathrm{p}, \mathrm{om}, i}
$$

$Y$ therefore tends to increase as the amounts of products increase because there is more PM into which partitioning can occur.

Odum et al. (13) utilized the above concepts of multicomponent G/P partitioning to develop a framework for parameterizing the trend of increasing $Y$ values with increasing $M_{\mathrm{t}}$ for chamber cases involving water-dry aerosols for which $M_{\mathrm{t}}=M_{\mathrm{o}}$. Assuming that the photooxidation of a parent hydrocarbon $\mathrm{HC}$ leads to just two overall final products $\mathrm{P}_{1}$ and $\mathrm{P}_{2}$, then

$$
\mathrm{HC}+\text { oxidants } \rightarrow p_{1} \mathrm{P}_{1}+p_{2} \mathrm{P}_{2},
$$

where $p_{1}$ and $p_{2}$ are molar stoichiometric coefficients. Reaction 7 will likely not represent a fundamental reaction because some initial products may only be transitory in the system.

Pankow et al. (15) discuss the facts that (a) the earliest studies of SOA yields were interpreted by assuming that each parent $\mathrm{HC}$ is characterized by a particular fixed value of $Y$ that is set by the stoichiometric coefficients of its condensable oxidation products; and $(b)$ for Reaction 7, the notion of fixed $Y$ values carries with it the requirement that $\mathrm{P}_{1}$ and $\mathrm{P}_{2}$ are of such low volatility that essentially $100 \%$ of any $P_{1}$ and $P_{2}$ produced will condense. For that case, for every $\mu \mathrm{g} / \mathrm{m}^{3}$ of $\mathrm{HC}$ that reacts, a certain fixed concentration of secondary organic PM will always 
form, and will equal (15)

$$
\begin{aligned}
& M_{\mathrm{o}}=\frac{1 \mu \mathrm{g}}{\mathrm{m}^{3}} \times\left(\frac{1}{\mathrm{MW}_{\mathrm{HC}} \times 10^{6}} \frac{\mathrm{mol} \mathrm{HC}}{\mu \mathrm{g}}\right) \\
& \times\left[\left(p_{1} \frac{\mathrm{mol} \mathrm{P}_{1}}{\mathrm{~mol} \mathrm{HC}}\right) \times\left(\mathrm{MW}_{\mathrm{P}_{1}} \times 10^{6} \frac{\mu{\mathrm{g} \mathrm{of} \mathrm{P}_{1}}}{\mathrm{~mol} \mathrm{P}_{1}}\right)\right. \\
& \left.+\left(p_{2} \frac{\mathrm{mol} \mathrm{P}_{2}}{\mathrm{~mol} \mathrm{HC}}\right) \times\left(\mathrm{MW}_{\mathrm{P}_{2}} \times 10^{6} \frac{\mu \mathrm{g} \mathrm{of} \mathrm{P}_{2}}{\mathrm{~mol} \mathrm{P}_{2}}\right)\right] \\
& =\frac{p_{1} \times \mathrm{MW}_{\mathrm{P}_{1}}}{\mathrm{MW}_{\mathrm{HC}}}+\frac{p_{2} \times \mathrm{MW}_{\mathrm{P}_{2}}}{\mathrm{MW}_{\mathrm{HC}}} \quad \text { units: }\left(\mu \mathrm{g} \text { of } \mathrm{P}_{1}+\mathrm{P}_{2}\right) / \mathrm{m}^{3}
\end{aligned}
$$

where each MW is a molecular weight, and $\alpha_{1}=p_{1} \times \mathrm{MW}_{\mathrm{P}_{1}} / \mathrm{MW}_{\mathrm{HC}}$ and $\alpha_{2}=$ $p_{2} \times \mathrm{MW}_{\mathrm{P}_{2}} / \mathrm{MW}_{\mathrm{HC}}$ are the mass stoichiometric factors for the production of $\mathrm{P}_{1}$ and $\mathrm{P}_{2}$ from the parent hydrocarbon.

Using the mass-based stoichiometric coefficients, $\alpha_{i}$, the result for of the overall yield $Y$ for a dry case is

$$
Y=\sum_{i} Y_{i}=\sum_{i} \alpha_{i}\left(\frac{K_{\mathrm{p}, \mathrm{om}, i} M_{\mathrm{o}}}{1+K_{\mathrm{p}, \mathrm{om}, i} M_{\mathrm{o}}}\right),
$$

where $Y_{i}$ is the individual contribution to the yield from compound $i$

$$
Y_{i}=\frac{M_{i}}{\Delta \mathrm{HC}},
$$

with $M_{i}\left(\mu \mathrm{g} \mathrm{m}^{-3}\right)$ being the contribution to $M_{\mathrm{o}}$ from component $i$.

The total amount $T_{i}$ of compound $i$ in the atmosphere will be distributed between the gas and particle phases so that

$$
T_{i}=A_{i}+F_{i}
$$

By the above arguments, then

$$
T_{i}=10^{3} \alpha_{i} \Delta \mathrm{HC}
$$

Note that $K_{\mathrm{p}, \mathrm{om}, i} M_{\mathrm{o}} /\left(1+K_{\mathrm{p}, \mathrm{om}, i} M_{\mathrm{o}}\right)$ is the fraction of $T_{i}$ that actually condenses to form aerosol, i.e., that

$$
\left(\frac{K_{\mathrm{p}, \mathrm{om}, i} M_{\mathrm{o}}}{1+K_{\mathrm{p}, \mathrm{om}, i} M_{\mathrm{o}}}\right)=\frac{F_{i}}{A_{i}+F_{i}} .
$$

The above framework has been used extensively in modeling yield data for laboratory smog chamber experiments conducted in the absence of water, using a wide range of parent $\mathrm{HC}$ compounds. Each of those experiments could be described by fitting the $Y$ versus $M_{\mathrm{o}}$ data by assuming that two hypothetical average product compounds $\mathrm{P}_{1}$ and $\mathrm{P}_{2}$ were formed. One of the products is an average 


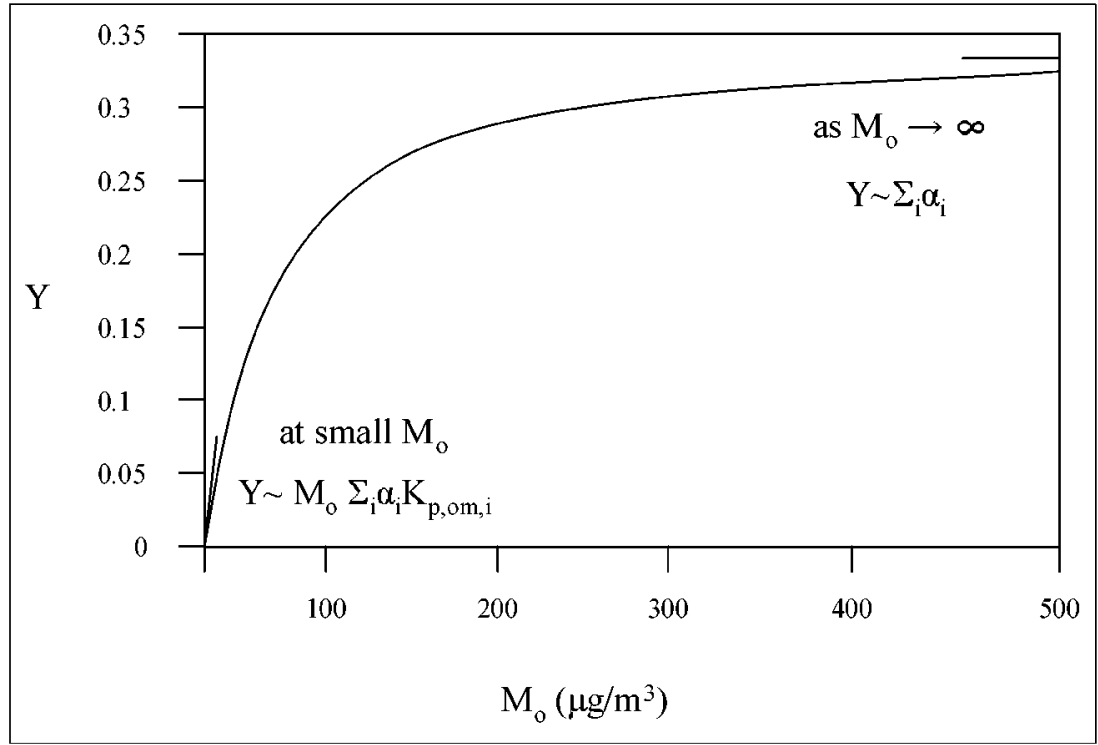

$$
Y=\sum_{i} Y_{i}=\sum_{i}\left(\frac{\alpha_{i} K_{p, o m, i} M_{o}}{1+K_{p, o m, i} M_{o}}\right)
$$

Figure 2 Behavior of the yield of secondary organic PM. At small $M_{\mathrm{o}}$, the yield depends directly on the amount of organic phase present, $M_{\mathrm{o}}$; at large $M_{\mathrm{o}}$, there is more than ample organic phase, and the yield depends only on the stoichiometric constants, $\alpha_{i}$.

for the lower vapor pressure compounds from the specific parent $\mathrm{HC}$; the other is an average for the remaining, higher vapor pressure compounds from that $\mathrm{HC}$. Yield data are not generally fit well by assuming a single product, and the assumption of three products does not improve the fits significantly. Figure 2 shows the characteristics of the secondary organic PM yield as a function of the amount of organic material already in the particulate phase. The limiting behaviors at low and high amounts of particulate organic are indicated. Notice that the yield approaches a constant value as the amount of particulate organic into which the gaseous products absorb reaches large values, and this asymptotic amount is determined purely by reaction stoichiometry. In a two-product fit, there are four fitting parameters: two $\alpha$ values and two $K_{\mathrm{p}, \mathrm{om}}$ values. In higher multiproduct modeling efforts in which specific oxidation products are considered, the photooxidation reaction pathways of parent HCs are not known in sufficient detail to allow compound-specific $\alpha_{i}$ values to be predicted reliably, even for relatively simple parent HCs, with the result that the needed $\alpha_{i}$ values for the products formed 
must currently be determined experimentally based on analyses of SOA formed in chambers.

The predictive modeling of real systems requires a product-specific model that accounts for the formation of secondary organic PM from all of the important individual products. Such a model requires $(a)$ the structures and $\alpha$ values for the products; $(b)$ the $p_{\mathrm{L}}^{\mathrm{o}}$ values for the products at the temperature of interest; and (c) means to estimate the compound-dependent particle-phase $\zeta_{i}$ values as a function of the particle phase composition and temperature. The simultaneous equations governing the equilibrium distribution of products can then be solved numerically by iteration as follows.

Pankow (12) gives a matrix representation of multicomponent G/P equilibrium. This representation relates the set of $F_{i}$ values to the corresponding set of $A_{i}$ values using the vectors $\hat{\mathbf{T}}, \hat{\mathbf{F}}$, and $\hat{\mathbf{A}}$. In a given photooxidation circumstance, a vector $\hat{\mathbf{T}}$ of total concentrations for the products will then produce a specific vector $\hat{\mathbf{Y}}$ of values $Y_{i}$. The input data for the algorithm are $\Delta \mathrm{HC}$ and the vector of $\alpha_{i}$ values with

$$
\hat{\mathbf{T}}=10^{3} \hat{\alpha} \Delta \mathrm{HC} .
$$

In the absence of water, the relationship between $\hat{\mathbf{F}}$ and $\hat{\mathbf{T}}$ is $(12,15)$

$$
\left[\begin{array}{c}
F_{1} \\
F_{2} \\
\cdot \\
F_{n}
\end{array}\right]=\frac{M_{\mathrm{o}} 760 R T}{10^{6} M W_{\mathrm{om}}} \times\left[\begin{array}{cccc}
\frac{\left(\zeta_{1} p_{\mathrm{L}, 1}^{\mathrm{o}}\right)^{-1}}{1+K_{\mathrm{p}, \mathrm{om}, 1} M_{\mathrm{o}}} & 0 & \cdot & \cdot \\
0 & \frac{\left(\zeta_{2} p_{\mathrm{L}, 2}^{\mathrm{o}}\right)^{-1}}{1+K_{\mathrm{p}, \mathrm{om}, 2} M_{\mathrm{o}}} & \cdot & \cdot \\
\cdot & \cdot & \cdot & \cdot \\
\cdot & \cdot & \cdot & \frac{\left(\zeta_{n} p_{\mathrm{L}, n}^{\mathrm{o}}\right)^{-1}}{1+K_{\mathrm{p}, \mathrm{om}, n} M_{\mathrm{o}}}
\end{array}\right]\left[\begin{array}{c}
T_{1} \\
T_{2} \\
\cdot \\
T_{n}
\end{array}\right] .
$$

For any $\hat{\mathbf{T}}$ and guess value of $M_{\mathrm{o}}$, Equation 16 can be solved iteratively to determine the corresponding solution $\hat{\mathbf{F}}$; in each iteration, the $\zeta_{i}$ values are needed.

Because water is ubiquitous in the atmosphere, ambient particles always contain some water. Thus, predicting the effects of water on the atmospheric G/P distributions of organic compounds is central to understanding atmospheric PM formation (19). For such cases, the system represented by Equation 16 is modified by substituting $M_{\mathrm{t}}$ for $M_{\mathrm{o}}$, and adding $A_{i}, F_{i}$, and $T_{i}$ values for water to the corresponding vectors. Indeed, the water will affect $f_{\mathrm{om}}, \mathrm{MW}_{\mathrm{om}}$ and the values of all $\zeta_{i}$. As a result, the extent of partitioning of each organic compound (as well as that of water) into a liquid aerosol PM phase will depend on the amount of water present. As RH increases, some partitioning organic compounds will be drawn more extensively into the aerosol PM phase, while some hydrophobic compounds may be driven out of the PM phase and back into the gas phase. For the partitioning of water, Saxena et al. (20) examined rural PM and concluded that the amount of water present was larger than could be accounted for based on water equilibrium with the inorganic components of the PM alone. Saxena \& Hildemann (21) have argued that the organic compounds that will be most affected by water in atmospheric aerosols are those that possesses multiple oxygen-containing groups (i.e., multiple 
alcohol, keto, aldehyde, and acid groups, and combinations thereof). Saxena \& Hildemann (21) identified the following as compound classes of special interest in this regard: $\mathrm{C}_{2}-\mathrm{C}_{7}$ polyols; $\mathrm{C}_{2}-\mathrm{C}_{7}$ amino acids; $\mathrm{C}_{2}-\mathrm{C}_{7}$ hydroxyl amines; and multifunctional $\mathrm{C}_{3}-\mathrm{C}_{6}$ compounds containing multiple hydroxyl, carboxyl, and carbonyl groups (e.g., glyceraldehydes, malic acid, citric acid, lactic acid, tartaric acid, and $\alpha$-ketoglutaric acid). The potential water-uptake roles of specific organic compounds such as di- and tri-carboxylic acids have been considered (22).

The chemical speciation of OC has been performed most often on a fraction obtained by extraction into a relatively nonpolar organic solvent such as benzene, diethyl ether, hexane, or dichloromethane. This fraction typically accounts for only $50-60 \%$ of the total organic PM mass (23). Polar compounds and water-soluble organic compounds (WSOCs) are often not extracted and hence not analyzed. Studies encompassing both urban and rural locations have reported that WSOCs are responsible for approximately $20-70 \%$ of the total particulate carbon in the atmosphere $(24,25)$.

The available studies on WSOCs have focused mainly on dicarboxylic acids, keto acids, and dicarbonyls. For urban aerosols as well as Antarctic and Arctic aerosols, these include $\mathrm{C}_{2}-\mathrm{C}_{9} \alpha, \omega$-dicarboxylic acids; $\mathrm{C}_{2}-\mathrm{C}_{9} \alpha$-oxo-carboxylic acids; pyruvic acid; and $\mathrm{C}_{2}-\mathrm{C}_{3}$ dicarbonyls $(24,26,27)$. In Arctic samples, $\mathrm{Li} \&$ Winchester (28) used ion chromatography to measure eight water-soluble organic acid anions, namely formate, acetate, oxalate, propionate, methanesulfonante, lactate, benzoate, and pyruvate. In a later study, Li et al. (29) measured a selected number of WSOCs including glyoxylic acid and five of the above organic acid anions (formate, acetate, propionate, oxalate, and methanesulfonate) in aerosol samples collected near the coast of Nova Scotia, Canada.

Since ambient secondary organic PM phase will contain some water, if $M_{\mathrm{o}}$ $\left(\mu \mathrm{g} \mathrm{m}^{-3}\right)$ is the organic-only portion and $M_{\mathrm{w}}\left(\mu \mathrm{g} \mathrm{m}^{-3}\right)$ is the water-only portion (see Equation 4), then

$$
Y_{\mathrm{o}}=\frac{M_{\mathrm{o}}}{\Delta \mathrm{HC}} \quad Y_{\mathrm{w}}=\frac{M_{\mathrm{w}}}{\Delta \mathrm{HC}}
$$

and

$$
Y_{\mathrm{t}}=\frac{M_{\mathrm{t}}}{\Delta \mathrm{HC}}=Y_{\mathrm{o}}+Y_{\mathrm{w}} .
$$

A compound-by-compound view of gas-particle partitioning can be obtained from the percentage of each compound that is present in the aerosol PM phase:

$$
\phi \times 100 \%=\frac{F}{A+F} \times 100 \% .
$$

A consideration of the effect of compound volatility on $\phi$ leads to the following three conclusions (19): (a) The $\phi$ values of very low $p_{\mathrm{L}}^{\mathrm{o}}$ value compounds will not be sensitive to changes in RH because high proportions in the secondary PM phase are not easily affected by changes in $K_{\mathrm{p}, \mathrm{om}} ;(b)$ the $\phi$ values of very high $p_{\mathrm{L}}^{\mathrm{o}}$ value compounds may be subject to significant changes with $\mathrm{RH}$, but the low proportion 
of such compounds in the secondary PM phase means that those compounds will have only small effect on $M_{\mathrm{o}}$ and $M_{\mathrm{w}}$ due to changes in RH; and (c) the $\phi$ values of intermediate $p_{\mathrm{L}}^{\mathrm{o}}$ value compounds will be subject to significant changes with RH and will contribute the most to changes in $M_{\mathrm{o}}$ and $M_{\mathrm{w}}$ because of changes in RH.

By Equation 3, increases in the $F / A$ ratio (i.e., increases in $\phi$ ) can be accomplished by $(a)$ reducing $\mathrm{MW}_{\mathrm{om}},(b)$ reducing $\zeta$, and $(c)$ increasing $f_{\mathrm{om}} \mathrm{TSP}\left(=M_{\mathrm{t}}\right)$. The first two increase $K_{\mathrm{p}}$; the third is a secondary consequence of generally increased $K_{\mathrm{p}}$ values. Equation 3 can be used to understand how increasing RH can affect $K_{\mathrm{p}}$ values by affecting the underlying $\mathrm{MW}_{\mathrm{om}}$ and $\zeta$ values. Following Seinfeld et al. (19), at constant temperature and pressure, the total derivative of $K_{\mathrm{p}}$ is given by

$$
d K_{\mathrm{p}}=\left(\frac{\partial K_{\mathrm{p}}}{\partial \mathrm{MW}_{\mathrm{om}}}\right) d \mathrm{MW}_{\mathrm{om}}+\left(\frac{\partial K_{\mathrm{p}}}{\partial \varsigma}\right) d \varsigma .
$$

By Equation 3,

$$
\left(\frac{\partial K_{\mathrm{p}}}{\partial \mathrm{MW}_{\mathrm{om}}}\right)=-\frac{760 R T f_{\mathrm{om}}}{10^{6} p_{\mathrm{L}}^{\mathrm{o}} \varsigma \mathrm{MW}_{\mathrm{om}}^{2}}=-\frac{K_{\mathrm{p}}}{\mathrm{MW}_{\mathrm{om}}},
$$

and

$$
\left(\frac{\partial K_{\mathrm{p}}}{\partial \varsigma}\right)=-\frac{760 R T f_{\mathrm{om}}}{10^{6} p_{\mathrm{L}}^{\mathrm{o}} \varsigma^{2} \mathrm{MW}_{\mathrm{om}}}=-\frac{K_{\mathrm{p}}}{\varsigma},
$$

so that

$$
d K_{\mathrm{p}}=-K_{\mathrm{p}}\left[\frac{d \mathrm{MW}_{\mathrm{om}}}{\mathrm{MW}_{\mathrm{om}}}+\frac{d \varsigma}{\varsigma}\right]
$$

or

$$
\begin{gathered}
d K_{\mathrm{p}}=-K_{\mathrm{p}}\left[d \ln \mathrm{MW}_{\mathrm{om}}+d \ln \varsigma\right], \\
\frac{d K_{\mathrm{p}}}{d \mathrm{RH}}=-K_{\mathrm{p}} \frac{d \ln \mathrm{MW}_{\mathrm{om}}}{d \mathrm{RH}}-K_{\mathrm{p}} \frac{d \ln \varsigma}{d \mathrm{RH}}, \\
\frac{d \ln K_{\mathrm{p}}}{d \mathrm{RH}}=-\frac{d \ln \mathrm{MW}_{\mathrm{om}}}{d \mathrm{RH}}-\frac{d \ln \varsigma}{d \mathrm{RH}} .
\end{gathered}
$$

As discussed by Seinfeld et al. (19), the first term in Equation 25 (including the minus sign) is a measure of the RH-induced effect on $K_{\mathrm{p}}$ caused by changes in $\mathrm{MW}_{\mathrm{om}}$. The second term (including the minus sign) is a measure of the RH-induced effect on $K_{\mathrm{p}}$ caused by changes in $\zeta$. For secondary PM formed from a variety of monoterpenes and cyclohexene, Seinfeld et al. (19) concluded that $\mathrm{d} K_{\mathrm{p}} / \mathrm{dRH}$ is positive over the entire RH range for all of the compounds considered. That is, increasing the RH leads to increases in $K_{\mathrm{p}}$ and therefore an increase in the overall extent of partitioning to the aerosol PM. They concluded that this result is owing in large part to the very low MW of water as compared to the MW values of the 
oxidation products: Adding water to the secondary PM phase uniformly reduces $\mathrm{MW}_{\text {om. }}$

As discussed by Seinfeld et al. (19), the contribution to $\mathrm{d} K_{\mathrm{p}} / \mathrm{dRH}$ from the $\zeta$ term is more complex than the contribution from the $\mathrm{MW}_{\mathrm{om}}$ term. Four behaviors can be identified. Type I: uniformly positive $(d \ln \zeta / d \mathrm{RH}$ uniformly $<0)$ across the RH range. Type II: at first positive $(d \ln \zeta / d \mathrm{RH}<0)$ at low $\mathrm{RH}$, then negative $(d \ln \zeta / d \mathrm{RH}>0)$ as more and more water is taken up by the secondary PM phase. Type III: uniformly negative $(d \ln \zeta / d \mathrm{RH}>0)$. Type IV: at first negative $(d \ln \zeta / d \mathrm{RH}>0)$ at low $\mathrm{RH}$, then positive $(d \ln \zeta / d \mathrm{RH}<0)$. A hydrophilic compound is expected to exhibit Type I behavior; a less hydrophilic compound is more likely to exhibit Type III behavior.

\section{EXPERIMENTAL STUDIES OF SECONDARY ORGANIC PM FORMATION}

Laboratory chambers are indispensable in the study of both gas-phase atmospheric chemistry and atmospheric aerosol formation and growth. Indeed, chamber studies provide a means to develop mechanistic understandings of individual chemical and microphysical processes that are known to occur in the atmosphere, but are very difficult to study there because of the confounding effects of complex flow and mixing processes. Measurements required in chamber experiments include gas-phase species concentrations and aerosol size distribution and composition. Measurements of aerosol microphysical properties, such as water uptake, are also useful.

Although a reaction vessel with a volume of a few liters strictly qualifies as a "chamber," studies of atmospheric chemistry, especially those involving aerosol formation, are best pursued using systems of at least a few cubic meters in volume. This is because small chambers are characterized by large surface area-to-volume ratios, a feature that makes them subject to significant losses of both gases and particles to the chamber walls.

For atmospheric chemistry processes that are driven by sunlight, chambers can be subdivided depending on whether natural or artificial sunlight is used. The principal advantage of outdoor chambers is the availability of natural sunlight; associated disadvantages arise from varying light intensity because of clouds, and from other uncontrollable weather aspects. Thus, replicating experimental conditions can be difficult with outdoor chambers. Indoor chambers afford precise control of light, temperature, and RH, but artificial lights may not simulate natural sunlight as closely as desired in some portions of the solar spectrum. Indoor and outdoor chambers may then be characterized by rate differences for certain photolysis reactions. In any event, although not identical to natural sunlight, artificial light will allow for experiments to be repeated under identical photolytic conditions.

Table 2 summarizes laboratory studies of secondary organic PM formation carried out over the last decade. Figures 3 and 4 show the variety of volatile organic compounds for which the potential for PM formation has been studied experimentally. Formation of secondary organic PM from terpenes of all structures 
TABLE 2 Laboratory studies of secondary organic aerosol formation

\begin{tabular}{|c|c|c|}
\hline Parent organic & Experimental conditions & References \\
\hline Automobile exhaust & $\mathrm{NO}_{\mathrm{x}}$ photooxidation & Kleindienst et al. (43) \\
\hline $\begin{array}{l}\text { Toluene, } p \text {-xylene, } \\
\text { 1,3,5-trimethylbenzene }\end{array}$ & $\mathrm{NO}_{\mathrm{x}}$ photooxidation & Kleindienst et al. (44) \\
\hline 1-tetradecene & $\mathrm{O}_{3}$ reaction & $\begin{array}{l}\text { Tobias \& Ziemann }(45,46) \\
\text { Tobias et al. }(47)\end{array}$ \\
\hline$\alpha$-pinene & $\mathrm{O}_{3}$ reaction & $\begin{array}{l}\text { Hoffmann et al. (48) } \\
\text { Schrader et al. (49) }\end{array}$ \\
\hline$\alpha$-pinene & $\mathrm{O}_{3}$ reaction & Kückelmann et al. (50) \\
\hline $\begin{array}{l}\alpha \text {-pinene, } \Delta^{3} \text {-carene, } \\
\beta \text {-pinene, sabinene, } \\
\text { limonene }\end{array}$ & OH reaction & Larsen et al. (51) \\
\hline Bornyl acetate & $\mathrm{OH}$ reaction & Coeur et al. (52) \\
\hline$\alpha$-pinene & $\mathrm{O}_{3}$ reaction & Jang \& Kamens (53) \\
\hline $\begin{array}{l}\text { Myrcene, ocimene, } \Delta^{3} \text {-carene, } \\
\alpha \text {-pinene, } \beta \text {-pinene, sabinene, } \\
\text { limonene, } \alpha \text {-terpinene, } \\
\gamma \text {-terpinene, terpinolene, } \\
\beta \text {-caryophyllene, } \alpha \text {-humulene, } \\
\text { linalool, terpinene-4-ol }\end{array}$ & $\mathrm{NO}_{\mathrm{x}}$ photooxidation & $\begin{array}{l}\text { Griffin et al. (54) } \\
\text { [see also earlier study } \\
\text { of Hoffmann et al. (55)] }\end{array}$ \\
\hline$\alpha$-pinene & $\mathrm{O}_{3}$ reaction; effect of $\mathrm{H}_{2} \mathrm{O}$ & Cocker et al. (56) \\
\hline$m$-xylene, 1,3,5-trimethylbenzene & $\begin{array}{l}\text { Photooxidation; effect } \\
\text { of } \mathrm{H}_{2} \mathrm{O}\end{array}$ & Cocker et al. (57) \\
\hline Cyclohexene & $\mathrm{O}_{3}$ reaction & Kalberer et al. (32) \\
\hline $\begin{array}{l}\alpha \text {-pinene, } \beta \text {-pinene, } \\
\Delta^{3} \text {-carene, sabinene }\end{array}$ & $\mathrm{O}_{3}$ reaction & Yu et al. $(39,58)$ \\
\hline Aromatics (17 species) & $\mathrm{NO}_{\mathrm{x}}$ photooxidation & $\begin{array}{l}\text { Odum et al. (59) } \\
\text { Forstner et al. (60) }\end{array}$ \\
\hline Gasoline vapor & $\mathrm{NO}_{\mathrm{x}}$ photooxidation & Odum et al. $(13,59)$ \\
\hline $\begin{array}{l}m \text {-xylene, 1,2,4-trimethylbenzene, } \\
\alpha \text {-pinene }\end{array}$ & $\mathrm{NO}_{\mathrm{x}}$ photooxidation & Odum et al. (13) \\
\hline 1-octene, 1 -decene & $\mathrm{NO}_{\mathrm{x}}$ photooxidation & Forstner et al. (61) \\
\hline$\alpha$-pinene & $\mathrm{NO}_{\mathrm{x}}$ photooxidation & Kamens \& Jaoui (62) \\
\hline Toluene & $\mathrm{NO}_{\mathrm{x}}$ photooxidation & Jang \& Kamens (63) \\
\hline Aldehydes & $\begin{array}{l}\text { Heterogeneous reaction } \\
\text { on acidic aerosols }\end{array}$ & Jang \& Kamens (64) \\
\hline
\end{tabular}


<smiles>Cc1cccc(C)c1</smiles>

m-xylene

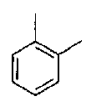

o-xylene

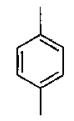

p-xylene<smiles>Cc1ccccc1</smiles>

toluene<smiles>CCc1ccccc1</smiles>

ethylbenzene

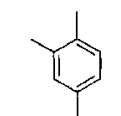

1,2,4-trimethylbenzene

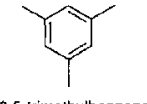

1,3,5-trimethylbenzene

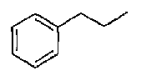

n-propylbenzene

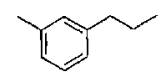

1-methyl-3-n-propylbenzene

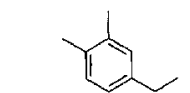

1,2-dimethyl-4-ethylbenzene



methyltoluene

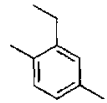

1,4-dimethyl-2-ethylbenzene

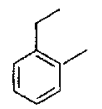

o-ethyholuene
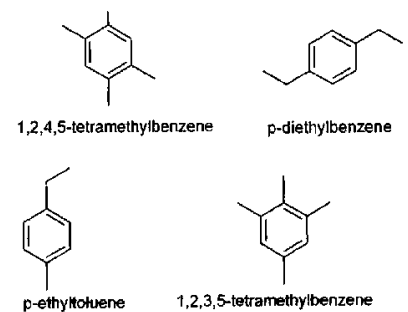

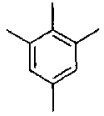

$1,2,3,5$-tetramethylbenzene

Figure 3 Aromatic hydrocarbons studied as precursors to secondary organic PM. All of these are found in the urban atmosphere.



Figure 4 Biogenic organics studied as precursors to secondary organic PM. 
is significant. The PM-forming potentials of these compounds exceed those of a typical aromatic constituent of gasoline, such as $m$-xylene. Of VOCs studied, sesquiterpenes exhibit the highest PM-forming potentials. This is a consequence of their higher numbers of carbon atoms, and therefore the low vapor pressures of their oxidation products.

The amount of aerosol formed from the atmospheric oxidation of VOCs depends on the structure of the parent molecule. For unsaturated molecules, the location of double bonds is important in determining the nature of the oxidation products. Cyclic structures generally have higher yields of secondary organic PM than acyclic compounds because most of the carbon backbone of cyclic compounds remains intact when the double bond(s) is (are) cleaved during oxidation. A main goal of current aerosol chamber experiments is to determine the aerosol formation potential of either a single parent $\mathrm{HC}$ or a mixture of parent $\mathrm{HCs}$, and to determine the molecular routes to particle formation through measurement of specific gasand aerosol-phase oxidation products.

\section{MOLECULAR MECHANISMS OF FORMATION OF SECONDARY ORGANIC PM}

Although many laboratory measurements of overall yields of secondary organic PM formation have been carried out, investigations of PM composition at the molecular level have only recently begun to identify appreciable fractions of the mass formed in chamber experiments. This work has been difficult because $(a)$ as noted above, parent $\mathrm{HC}$ compounds that lead to secondary PM generally contain six or more carbon atoms; and $(b)$ atmospheric oxidation pathways of $\geq \mathrm{C}_{6}$ compounds lead to a relatively large number of products that are generally highly polar and difficult to identify and determine.

The molecular identification of gas- and aerosol-phase products will serve as a basis for evaluating the ability to predict organic PM formation from first principles. Indeed, if one knows all of the semivolatile oxidation products from a parent $\mathrm{HC}$ together with their extents of formation and their physical properties (most importantly $p_{\mathrm{L}}^{\mathrm{o}}$ ), then the yield of secondary PM from that parent molecule should be predictable for any given set of temperature and $\mathrm{RH}$ conditions.

A number of the studies cited in Table 2 discuss the identification of specific gas- and/or particle-phase products, and a few postulate the overall atmospheric photooxidation mechanisms that brought about the observed products. In addition, Calvert et al. (30) survey available results on product identification and photooxidation mechanisms for secondary organic PM from aromatic parent HCs. Because of the difficulties in identifying highly polar, relatively nonvolatile organic molecules, in general, the complete knowledge of molecular pathways leading to secondary PM products is certainly not available, although significant progress has been made recently for the important biogenic hydrocarbons such as $\alpha$ - and $\beta$-pinene (31). We also note that cyclohexene-ozone is a useful model system because gasand aerosol-PM-phase products have been reasonably well characterized (32). However, even for a system as "simple" as cyclohexene-ozone, the number of 
significant aerosol-phase products is at least ten. Pankow et al. (15) compared, observed, and predicted yield values for secondary organic PM formed from cyclohexene-ozone, and from monoterpene-ozone systems; in general good agreement was obtained.

\section{INSIGHTS ON SECONDARY ORGANIC PM FROM AMBIENT DATA}

The composition of ambient organic PM can be used to obtain some insights into the chemical pathways and magnitude of secondary organic PM formation in the atmosphere by employing (a) OC and EC data to estimate the overall magnitude of secondary organic PM formation; (b) data on organic compound classes (e.g., carbonyl groups and organonitrate groups) to assess the magnitude of secondary organic PM formation and the approximate composition of that PM; $(c)$ concentrations of molecular tracers to assess the role of individual hydrocarbon precursors in secondary organic PM formation.

The first approach involves the computation of the OC/EC ratio (33-35). By assuming that all of the EC is primary and that a given primary PM has a characteristic OC/EC ratio, it is possible to estimate the fraction of the organic PM that is primary in origin. The remainder is assumed to be secondary. Although the accuracies of such estimates are highly dependent on accurate values for the OC/EC ratio in the local primary PM, those values are frequently not well known. As a result, such estimates of secondary organic PM formation are usually uncertain. Nevertheless, because clearly better methods are currently lacking, the OC/EC approach is expected to see continued common use.

Application of the second, functional group approach, has been attempted using infrared spectroscopy (36). In these measurements, the organic fraction of an ambient sample is typically assumed to consist of a limited number of structural elements. These include aliphatic carbon and hydrogen, aromatic carbon and hydrogen, carbonyl groups, nitroaromatic groups, and a few other functional groups. Some of the functional groups (e.g., keto, aldehyde, and organonitrate groups) are assumed to be limited almost exclusively to the secondary organic portion of the PM. The amounts of those groups together with assumptions about average structures of the compounds that comprise the secondary organic PM can then be used to estimate total secondary organic PM concentrations. While this method is certainly not absolute, it is quite complementary to the OC/EC approach.

The OC/EC and functional group approaches do not identify the parent HCs that led to the secondary organic PM. The study of ambient organic PM for that purpose would require as a first, difficult step, the reliable compound-by-compound identification of the important condensed compounds. A next, difficult step would involve mechanistic rationalizations based on poorly-known gas-phase photooxidation reaction pathways and stoichiometries. The simplest type of organic PM for this approach might be one for which the parent HCs are of a single limited type, as with biogenic PM. 
Several recent studies have provided evidence of either nucleation or condensation of oxidation products of biogenic hydrocarbons in forest atmospheres (37-40). Drawing on prior results of monoterpene product analysis under controlled laboratory conditions, Yu et al. $(39,65)$ identified organic PM components attributable to monoterpene oxidation in forest atmospheres in California and Nova Scotia. O'Dowd et al. (40) present convincing evidence that nascent particles $(3-5 \mathrm{~nm}$ diameter) from a nucleation event in a boreal forest in Finland were composed primarily of organic compounds such as cis-pinonic and pinic acids from the oxidation of terpenes.

\section{CONCLUSIONS}

Understanding the sources, molecular composition, and chemistry of atmospheric organic particulate matter represents a key problem in atmospheric chemistry. Direct emission of carbonaceous particulate material into the atmosphere occurs from a variety of combustion processes. Secondary organic PM arises when volatile organic compounds (VOCs) are oxidized in the atmosphere to form products that have sufficiently low volatility to partition between the gas and particulate phases. These products tend to be highly oxidized, polar organic molecules containing six or more carbon atoms. The partitioning is determined by the dissolution of the low-vapor pressure organics into a particulate phase that consists in general of a mixture of already condensed organic compounds, primary carbonaceous PM, water, and dissolved inorganic electrolytes. (Whether phase separation between hydrophilic and hydrophobic phases occurs within individual particles themselves is a subject of current inquiry.) The equilibrium-phase partitioning depends strongly on temperature, because of the variation of vapor pressures of the condensing compounds with temperature, and less so, but still importantly, on relative humidity, which governs the amount of water in the particulate phase. To predict gas/particle partitioning on first principles requires knowledge of compound vapor pressures, which, in many cases, have not been measured and therefore must be estimated using molecular models. Because the organic/organic and organic/water mixtures in atmospheric PM are nonideal, prediction also requires values of liquid-phase activity coefficients. Underlying the entire issue of predicting secondary organic PM prediction is the fact that molecular identification of the oxidation products of the higher molecular weight VOCs that are the sources of that PM remains an extremely difficult problem. Laboratory measurements of the overall mass yields of aerosol from oxidation of individual VOCs provide the fundamental data to test first-principles prediction of aerosol formation, but molecular product identification remains a key component in such predictions.

\section{ACKNOWLEDGMENT}

This research was supported in part by the Biological and Environmental Research Program (BER), U.S. Department of Energy, grant number DE-FG03-01ER63099. 


\section{The Annual Review of Physical Chemistry is online at http://physchem.annualreviews.org}

\section{LITERATURE CITED}

1. Intergov. Panel Climate Change (IPCC). 2001. Climate Change 2001. Cambridge, UK: Cambridge Univ. Press

2. U.S. Environ. Protection Agency. 1996. Air Quality Criteriafor Particulate Matter. EPA/600/P-95/001. Washington, DC: EPA

3. Jacobson MC, Hansson HC, Noone KJ, Charlson RJ. 2000. Rev. Geophys. 38:26794

4. Turpin BJ, Saxena P, Andrews E. 2000. Atmos. Environ. 34:2983-3014

5. Liousse C, Penner JE, Chuang C, Walton JJ, Eddleman H, Cachier H. 1996. J. Geophys. Res. 101:19411-32

6. Cooke WF, Wilson JJN. 1996. J. Geophys. Res. 101:19395-409

7. Cooke WF, Liousse C, Cachier H, Feichter J. 1999. J. Geophys. Res. 104:22137162

8. Bond TC. 2000. Light absorption by primary particles from fossil fuel combustion: implications for radiative forcing. $\mathrm{PhD}$ thesis. Univ.Wash., Seattle. 383 pp.

9. Penner JE, Eddlemann H, Novakov T. 1993. Atmos. Environ. 27A:1277-95

10. Schuetzle D, Rasmussen RA. 1978. J. Air Pollut. Control Assoc. 28:236-40

11. Pankow JF. 1994. Atmos. Environ. 28:18588

12. Pankow JF. 1994. Atmos. Environ. 28:18993

13. Odum JR, Hoffmann T, Bowman F, Collins D, Flagan RC, Seinfeld JH. 1996. Environ. Sci. Technol. 30:2580-85

14. Seinfeld JH, Pandis SN. 1998. Atmospheric Chemistry and Physics. New York: Wiley. 1326 pp.

15. Pankow JF, Seinfeld JH, Asher WE, Erdakos GB. 2001. Environ. Sci. Technol. 35:1164-72

16. Hilal SH, Carreira LA, Karickhoff SW. 1994. Quantitative Treatments of Solutel Solvent Interactions. Amsterdam: Elsevier. $380 \mathrm{pp}$.
17. Makar PA. 2001. Atmos. Environ. 35:96174

18. Asher WE, Pankow JF, Erdakos GB, Seinfeld JH. 2002. Atmos. Environ. 36:148398

19. Seinfeld JH, Erdakos GB, Asher WE, Pankow JF. 2001. Environ. Sci. Technol. 35:1806-17

20. Saxena P, Hildemann LM, McMurry PH, Seinfeld JH. 1995. J. Geophys. Res. 100: 18755-70

21. Saxena P, Hildemann LM. 1996. J. Atmos. Chem. 24:57-109

22. Ansari AS, Pandis SN. 2000. Environ. Sci. Technol. 34:71-77

23. Cass G. 1998. Trends Anal. Chem. 17:35665

24. Sempere R, Kawamura K. 1994. Atmos. Environ. 28:449-59

25. Mueller PK, Fung KK, Heisler SL, Grosjean D, Hidy GM. 1982. Atmospheric particulate carbon observations in urban and rural areas of the United States. In Particulate Carbon-Atmospheric Life Cycle, ed. GT Wolff, RL Klimisch, pp. 343-70. New York: Plenum. 411 pp.

26. Kawamura K, Semere R, Imai Y, Fujii Y, Hayashi M. 1996. J. Geophys. Res. 101:18721-28

27. Kawamura K, Kasukabe H, Barrie LA. 1996. Atmos. Environ. 30:1709-22

28. Li S-M, Winchester JW. 1993. Geophys. Res. Lett. 20:45-48

29. Li S-M, Banic CM, Leaitch WR, Liu PSK, Isaac GA, et al. 1996. J. Geophys. Res. 101:29111-21

30. Calvert JG, Atkinson R, Becker KH, Kamens RM, Seinfeld JH, et al. 2002. The Mechanisms of Atmospheric Oxidation of Aromatic Hydrocarbons. New York: Oxford Univ. Press. $556 \mathrm{pp}$.

31. Jenkin ME, Shallcross DE, Harvey JN. 2000. Atmos. Environ. 34:2837-50

32. Kalberer M, Yu J, Cocker DR III, Flagan 
RC, Seinfeld JH. 2000. Environ. Sci. Technol. 34:4894-901

33. Turpin BJ, Huntzicker JJ. 1991. Atmos. Environ. 25:207-13

34. Turpin BJ, Huntzicker JJ, Larson SM, Cass GM. 1991. Environ. Sci. Technol. 25:178893

35. Gray HA, Cass GR, Huntzicker JJ, Heyerdalh EK, Rau JA. 1986. Environ. Sci. Technol. 20:580-89

36. Allen DT, Palen EJ, Haimov MI, Hering SV, Young JR. 1994. Aerosol Sci. Technol. 21:325-42

37. Kavouras IG, Mihalopoulos N, Lemonakis A, Stehanou EG. 1998. Nature 395:683-86

38. Leaitch WR, Bottenheim JW, Biesenthal TA, Li S-M, Liu PSK, et al. 1999. J. Geophys. Res. 104:8095-111

39. Yu J, Cocker DR III, Griffin RJ, Flagan RC, Seinfeld JH. 1999. J. Atmos. Chem. 34:207-58

40. O'Dowd CD, Aalto P, Hämeri K, Kulmala M, Hoffmann T. 2002. Nature 416:497

41. Guenther A, Hewitt CN, Erickson D, Fall R, Geron C, et al. 1995. J. Geophys. Res. 100:8873-92

42. Griffin RJ, Dabdub D, Cocker DR III, Seinfeld JH. 1999. Geophys. Res. Lett. 26:2721-24

43. Kleindienst TE, Corse EW, Li W, McIver CD, Conver TS, et al. 2002. J. Air Waste Manag. Assoc. 52:259-72

44. Kleindienst TE, Smith DF, Li W, Edney EO, Driscoll DJ, et al. 1999. Atmos. Environ. 33:3669-81

45. Tobias HJ, Ziemann PJ. 2000. Environ. Sci. Technol. 34:2105-15

46. Tobias HJ, Ziemann PJ. 2001. J. Phys. Chem. 105:6129-35

47. Tobias HJ, Docherty KS, Beving DE, Ziemann PJ. 2000. Environ. Sci. Technol. 34:2116-25

48. Hoffmann T, Bandur R, Marggraf U, Lin- scheid M. 1998. Atmos. Environ. 32:165761

49. Schrader W, Geiger J, Hoffmann T, Klockow D, Korte E-H. 1999. J. Chromatogr. A 864:299-314

50. Kückelmann U, Warscheid B, Hoffmann T. 2000. Anal. Chem. 72:1905-12

51. Larsen BR, Di Bella D, Glasius M, Winterhalter R, Jensen NR, Hjorth J. 2001. J. Atmos. Chem. 38:231-76

52. Coeur C, Jacob V, Foster P. 1999. Atmos. Environ. 33:1615-20

53. Jang M, Kamens RM. 1999. Atmos. Environ. 33:459-74

54. Griffin RJ, Cocker DR III, Flagan RC, Seinfeld JH. 1999. J. Geophys. Res. 104:355567

55. Hoffmann T, Odum JR, Bowman F, Collins D, Klockow D, et al. 1997. J. Atmos. Chem. 26:189-222

56. Cocker DR III, Clegg SL, Flagan RC, Seinfeld JH. 2001. Atmos. Environ. 35:6049-72

57. Cocker DR III, Mader BT, Kalberer M, Flagan RC, Seinfeld JH. 2001. Atmos. Environ. 35:6073-85

58. Yu J, Flagan RC, Seinfeld JH. 1998. Environ. Sci. Technol. 32:2357-70

59. Odum JR, Jungkamp TPW, Griffin RJ, Forstner HJL, Flagan RC, Seinfeld JH. 1997. Science 276:96-99

60. Forstner HJL, Flagan RC, Seinfeld JH. 1997. Environ. Sci. Technol. 31:1345-58

61. Forstner HJL, Seinfeld JH, Flagan RC. 1997. Atmos. Environ. 31:1953-64

62. Kamens RM, Jaoui M. 2001. Environ. Sci. Technol. 35:1394-1405

63. Jang M, Kamens RM. 2001. Environ. Sci. Technol. 35:4758-66

64. Jang M, Kamens RM. 2001. Environ. Sci. Technol. 35:3626-39

65. Yu J, Griffin RJ, Cocker DR III, Flagan RC, Seinfeld JH, Blanchard P. 1999. Geophys. Res. Lett. 26:1145-48 
R

Volume 54, 2003

\section{CONTENTS}

Frontispiece-Richard Bersohn

xiv

Some Pleasures in Chemical Physics, Richard Bersohn

In SEARCH OF PERFECTION: Understanding THE Highly

DeFECT-SELECTIVE CHEMISTRY OF ANISOTROPIC ETCHING, Melissa A. Hines

LONG-RANGE RESONANCE ENERGY TRANSFER IN MOLECULAR SYSTEMS, Gregory D. Scholes

FEMTOSECOND TIME-RESOLVED PHOTOELECTRON SPECTROSCOPY OF POLYATOMIC MOLECULES, Albert Stolow

Organic AtMospheric Particulate Material, John H. Seinfeld and James F. Pankow

CONJUGated Polymers as MOlecular Materials: How Chain CONFORMATION AND FILM MORPHOLOGY INFLUENCE ENERGY TRANSFER AND INTERCHAIN INTERACTIONS, Benjamin J. Schwartz

MOLECUlar ASPECTS OF HALIDE ION HydRATION: THE Cluster APPROACH, William H. Robertson and Mark A. Johnson

StATE-RESOlVED DyNAMICS OF PHOTOFRAGMENTATION, Yuan-Pern Lee

Master Equation Models for ChemiCAl Reactions of IMPORTANCE IN COMBUSTION, Michael J. Pilling and Struan H. Robertson

Optical Diagnostics for Thin FiLm Processing, Irving P. Herman

STM CONTROL OF CHEMICAL REACTIONS: Single-MoleCULE

SYNTHESIS, Saw-Wai Hla and Karl-Heinz Rieder

307

Optical PROPERTIES AND UltRAFAST DyNAMics OF METALliC

NANOCRYSTALS, Stephan Link and Mostafa A. El-Sayed

THEORY OF Dipole-Bound ANIONS, Kenneth D. Jordan and Feng Wang

Photoelectron Angular Distributions, Katharine L. Reid

Two-Dimensional FEMTOSECOND SPECTROSCOPY, David M. Jonas

TUNNELING AND OPTICAL SPECTROSCOPY OF SEMICONDUCTOR

NANOCRYSTALS, Uri Banin and Oded Millo 
QuANTUM SCATTERING CALCULATIONS ON CHEMICAL REACTIONS,

Stuart C. Althorpe and David C. Clary

STRUCTURAL STUdiES OF BIOMATERIALS USING DOUBLE-QUANTUM

SOLID-STATE NMR SPECTROSCOPY, G.P. Drobny, J.R. Long,

T. Karlsson, W. Shaw, J. Popham, N. Oyler, P. Bower, J. Stringer,

D. Gregory, M. Mehta, and P.S. Stayton

INDEXES

Subject Index

573

Cumulative Index of Contributing Authors, Volumes 50-54 597

Cumulative Index of Chapter Titles, Volumes 50-54

600

\section{ERRATA}

An online log of corrections to Annual Review of Physical Chemistry

chapters may be found at http://physchem.annualreviews.org/errata.shtml 